\title{
Le virus d'Epstein-Barr et les proliférations lymphoïdes
}

Laure Marelle Delphine Rea Martine Raphäl

\section{ADRESSES}

L. Marelle: docteur en médecine, interne des hôpitaux de Paris. Laboratoirc de neuropathologic, hôpital Pitié-Salpêtrière, 47, boulevard de l'Hôpital, 75651 Paris Cedex 13, France. D. Rea : interne des hôpitaux de Paris, DEA de virologie médicale, Institut Pasteur, Universite Paris VI. M. Raphaël : docteur en médecine, docteur en biologie humaine, maître de conférences des universités, praticien hospitalier. Centre d'écologic cellulaire, département d'hématologie, hôpital Pitié-Salpĉtric̀re, 47, boulevard de l'Hôpital, 75651 Paris Cedex 13, France.

$\mathrm{m} / \mathrm{s} n^{\circ} \quad 6-7$ vol. 9, juin-juillet 93

C'est de plus en plus fréquemment que le virus d'Epstein-Barr (EBV) est associé à des proliférations lymphoïdes. Cette augmentation est liée à la plus grande fréquence des déficits immunitaires acquis, iatrogènes ou viraux, et à la grande sensibilité des nouvelles méthodes de détection, PCR et hybridation in situ. A côté des proliférations lymphoïdes associées à l'EBV dans plus de $90 \%$ des cas, comme le lymphome de Burkitt africain et les syndromes lymphoprolifératifs compliquant des déficits immunitaires chez des transplantés, les lymphomes développés au cours de l'infection par le VIH occupent une place particulière. Ils sont associés à l'EBV dans 10 à $100 \%$ des cas selon leur type histologique et leur localisation. Récemment, la présence de l'EBV a aussi été démontrée dans certaines catégories de lymphomes $T$ et dans la maladie de Hodgkin survenant chez les sujets immunocompétents. L'analyse des réponses immunes anti-EBV, de l'expression des gènes de latence et de réplication virale, et des modifications phénotypiques et génotypiques des cellules tumorales infectées, devrait permettre de mieux comprendre le rôle tumorigène exact de l'EBV.

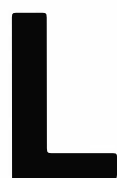

'implication de l'EBV dans les proliférations lymphoïdes a été évoquée dès sa découverte dans une lignée de lymphome de Burkitt africain [1]. Lc virus est détecté dans les cellules de la plupart des proliférations lymphoïdes qui surviennent lors des déficits immunitaires congénitaux ou acquis. Ces proliférations sont caractérisées par leur divcrsité morphologique, immunophénotypique et génotypique. L'activation cellulaire $B$ polyclonale, l'infection des lymphocytes B et des lymphocytes T, le maintien de l'état de latence, les possibles intégration et réplication de l'EBV dans les cellules lymphoïdes, et la rupture de l'équilibre virus-hôte contrôlé par les lymphocytes T cytotoxiques, sont autant de facteurs intervenant dans l'apparition des maladies lymphoprolifératives liées à l'EBV.

$L^{\prime} E B V$, virus de la famille des Herpesviridae est un virus ubiquitaire

L'EBV possède un spectrc d'hôte 


\section{RÉFÉRENCES}

1. Epstein MA, Achong BG, Barr YM. Virus particles in cultured lymphoblasts from Burkitt's lymphoma. Lancet 1964; 1 702.

2. Gratama JW, Oosterveer MAP, Zwaan FE, Lepoutre J, Klein G, Ernberg I. Eradication of Epstein-Barr virus by allogenic bonc-marrow transplantation : implications for sites of viral latency. Proc Natl Acad Sci USA 1988 ; 85 : 8693-6.

3. Fischer E, Delibrias C, Kazatchkine MD. Expression of CR2 (the C3dg/EBV receptor, CD21) on normal human peripheral blood T lymphocytes. I Immunol 1991 ; 146 865-9.

4. Sixbey JW, Yao QY. Immunoglobulin A-induced shift of Epstein-Barr virus tissuc tropism. Science 1992; 255 : 1578-80.

5. Baer C, Bankier AT, Biggin MD, et al. DNA sequence and expression of the B95-8 Epstein-Barr virus genome. Nature 1984 ; 310: 207-11

6. Raab-Traub N, Flynn K. The structure of the termini of the Epstein-Barr virus as a marker of clonal cellular proliferation. Cell $1986 ; 47: 883-9$

7. Adldinger HK, Delius $H$, Freese UK, Clarke J, Bornkamm GW. A putative transforming gene of Jijoye virus differs from that of Epstein-Barr virus prototypes. Virology $1985 ; 141: 221-34$.

8. Hurley EA, Agger S, McNeil A, I a awrence JB, Calender A, I,enoir G, ThorleyLawson DA. When Epstein-Barr virus persistently infects B-cell lines, it frequently integrates. I Virol 1991; 65 : 1245-54. 9. Jat P, Arrand JR. In vitro transcription of two Epstein-Barr virus specificd small RNA molecules. Nucleic Acids Res 1982 ; 10 : 3407-25

10. Cohen JI, Wang F, Mannick J, Kieff E. Epstein-Barr virus nuclear protein 2 is a key determinant of lymphocyte transformation. Proc Natl Acad Sci USA 1989 ; 86 : 9558-62

11. Wang F, Gregory C, Sample M, et al. Epstein-Barr virus latent membrane protein (LMP1) and nuclear proteins 2 and $3 \mathrm{C}$ are effectors of phenotypic changes in B lymphocytes : EBNA2 and LMP1 cooperatively induce CD23. J Virol 1990 ; 64 : 2309-18.

12. Abbot SD, Rowe M, Cadwallader K, et al. Epstein-Barr virus nuclear antigen 2 induces expression of the encoded latent membrane protein. J Virol 1990; 64: 2126-34.

13. Wang D, I icbowitz D, Kicff E. An EBV membrane protein expressed in immortalized lymphocytes transforms established rodent cells. Cell 1985 ; 43 : 831-40. 14. Dawson CW, Rickinson AB, Young LS. Epstein-Barr virus latent membrane protein inhibits human epithelial cell differenciation. Nature $1990 ; 344$ : 777-80. 15. Henderson S, Rowe M, Gregory C, et al. Induction of bcl-2 expression by EpsteinBarr virus latent membrane protein 1 protects infected B-cells from programmed cell death. Cell 1991; 65 : 1107-15.

16. Miller $G$. The switch between latency and replication of Epstein-Barr virus. I Infect Dis $1990 ; 161$ : 833-44. réduit à l'homme et au singe tamarin (90\% de la population humaine adulte est infectée par ce virus). La primo-infection survient après contact salivaire oropharyngé pendant l'enfance ou l'adolescence. Elle est le plus souvent silencieuse, mais elle peut être symptomatique et responsable de la mononucléose infectieuse lorsqu'elle survient tardivement. Les lymphocytes $B$ infectés sont activés et prolifèrent de façon polyclonale. Cette prolifération lymphocytaire B est contrôlée par les cellules cytotoxiques de l'hôte. Après la primo-infection, le virus persiste dans l'organisme, et il s'établit alors un équilibre entre le virus et l'hôte. Les cellules épithéliales de l'oropharynx sont à la fois le site primaire de l'infection et le lieu privilégié de la production virale à partir duquel s'infecteraient les lymphocytes B pendant leur passage dans les tissus lympho-épithéliaux pharyngés. Il existe deux réservoirs de virus dans l'organisme : les cellules épithéliales oropharyngées et les compartiments lymphoïdes [2]. Parmi les lymphocytes B circulants, une cellule sur 100000 à 10000000 est infectée par l'EBV à l'état latent, mais des réactivations intermittentes pcuvent survenir. L'EBV se fixe sur les lymphocytes $B$ et très vraisemblablement sur les lymphocytes $T$ [3] par interaction entre la glycoprotéine d'enveloppe virale gp350/220 et la molécule $\mathrm{CD} 21$, récepteur des fractions C3d et $\mathrm{C} 3 \mathrm{~g}$ du complément ou $\mathrm{CR} 2$. In vitro, les lymphocytes B peuvent être facilement infectés. En rcvanche, dans certaines cellules épithéliales, la pénétration du virus serait facilitée par la fixation préalable d'immunoglobulines A sur les antigènes de capside VCA (viral capsid antigens) [4].

\section{L'organisation des gènes viraux (figure 1)}

L'EBV est un virus à ADN bicaténaire de $172 \mathrm{~kb}$, qui se réplique dans le noyau des cellules infectées. Le génome du virus infectant la lignée cellulaire B95-8 a été entièrement séquencé [5]. Le génome est organisé en cinq domaines uniques, U1 à U5, séparés par des séquences internes, IR (internal repeat), répétées en tandem. Les séquences répétées termina- les (terminal repeat) TR, situées à chaque extrémité du génome permettent la circularisation sous forme d'épisome. L'analyse de ces séquences permet de déterminer la clonalité de l'infection [6]. Le virus possède une origine de réplication latente (OriP) et deux origines de réplication lytique homologues (Orilyt) situées dans les séquences DR et DL. L'initiation de la transcription des gènes des EBNA (Epstein-Barr virus nuclear antigens) peut s'effectuer à partir de trois promoteurs $C p$, $W p$ ou $F p$. Deux sous-types de virus ont été identifiés, se différenciant par l'antigène EBNA2 : EBNA2A et 2B [7].

Pendant la phase de latence, le génome de l'EBV est maintenu sous forme épisomique extrachromosomique, fixé à la membrane nucléaire par une séquence intéressant oriP. Le génome viral peut s'intégrer dans l'ADN cellulaire de certaines lignées infectées de façon latente et coexister avec l'ADN épisomique. Le plus souvent, l'intégration survient par l'intermédiaire des séquences TR, et l'ADN viral est intégré dans sa totalité. Dans certains cas, l'intégration aboutit à une délétion intéressant la séquence oriP. Les sites de l'intégration restent encore mal connus, et son rôle éventuel dans les processus de transformation cellulaire reste à déterminer [8].

\section{L'expression de I'EBV pendant la phase de latence (figure 2, p. 697)}

Dans certaines lignées cellulaires obtenues à partir de lymphocytes B de porteurs sains du virus, un nombre restreint de gènes sont exprimés : six protéines nucléaires EBNA 1, 2, 3A, 3B, LP (leader protein) et $3 \mathrm{C}$, trois protéines membranaires LMP (latent membrane proteins) $1,2 \mathrm{~A} / 2 \mathrm{~B}$, et deux ARN nucléaires non codants EBER 1 et 2 ( $E B V$ encoded small RNAs) [9]. Les EBER sont abondamment exprimés à raison de $10^{7}$ copies par cellule ; ils joueraient un rôle dans la maturation des ARN viraux. La protéine EBNA1 est impliquée dans le maintien de l'EBV sous forme épisomique et dans la réplication de l'épisome. EBNA2 et LMP auraient un rôle fondamental dans la transformation et l'immortalisation cellulaire. 


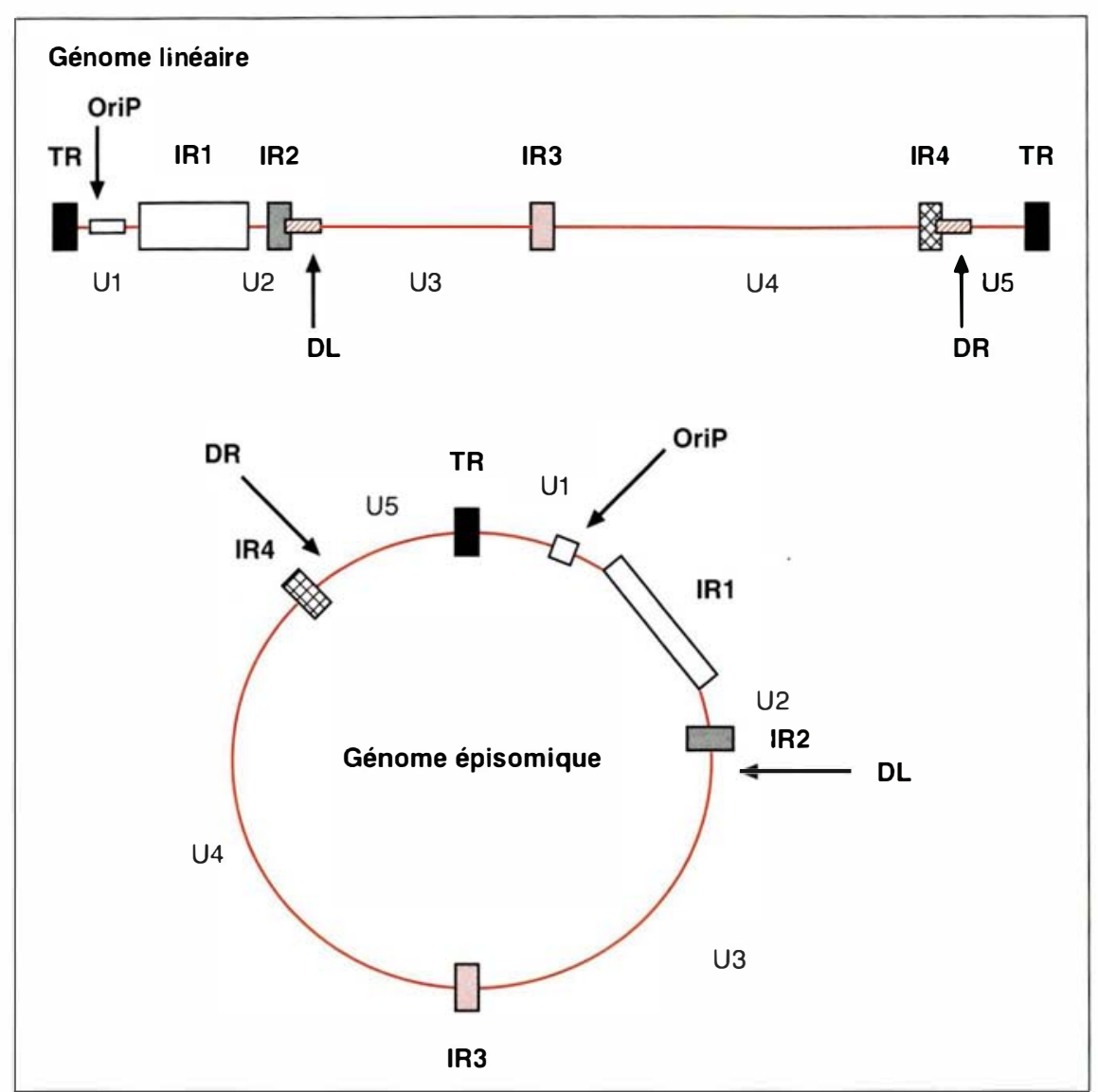

Figure 1. Organisation du génome de I'EBV sous forme linéaire et épisomique (172 kilobases). TR : séquences terminales répétées; U1 à U5: séquences uniques; IR : séquences internes répétées; OriP : origine de réplication latente; $D L$ et $D R$ : séquences homologues contenant les origines de réplication lytique Orilyt. (D'après [19].)

EBNA2 induit l'expression des marqucurs lymphocytaires B CD21 et CD23 [10, 11], et transactive le gène codant pour LMP [12]. LMP aurait des fonctions similaires à celles d'un oncogc̀ne [13]. Dans les cellules épithéliales humaines, la transfection de LMP provoque des modifications phénotypiques analogues à celles qui sont induites par l'oncogène ras et inhibe la différenciation cellulaire terminale [14]. Dans les cellules lymphoïdes, LMP induit l'expression du proto-oncogène cellulaire $b c l 2$, protégeant les cellules infectées de l'apoptose [15].

\section{L'expression de I'EBV} pendant la phase lytique (figure 2)

L'entrée dans le cycle réplicatif est $\begin{array}{lllll}m / s & n^{\circ} & 6-7 & \text { vol. } 9 \text {, juin-juillet } 93\end{array}$ latence après l'infection des lymphocytes [17]. Après la réplication du génome viral, les antigc̀nes tardifs MA (membrane antigens), VCA et BCRF1 sont exprimés. BCRF1 possc̀de $70 \%$ d'homologic avec l'interleukine 10 et inhibe la synthèse d'interféron $\gamma$ normalement impliqué dans les défenses immunitaires antivirales [18].

\section{Les lignées cellulaires infectées par I'EBV in vitro}

Les interactions entre l'EBV et le lymphocytc $B$ ont été bien caractérisées in vitro. Il existc deux types de lignées cellulaires infectées par l'EBV : les lignées cellulaires lymphoblastoïdes issues de lymphocytes B normaux circulants et les lignées de ccllules de lymphome de Burkitt. Ces deux lignécs diffèrent par leur phénotype et l'expression des gènes viraux. Les cellules des lignées lymphoblastoïdes ne sc multiplient pas en gélose scmi-molle et n'induisent pas de tumeur chez la souris nude. En culture, elles ont un aspect polymorphe avec une différenciation plasmocytoïde. Elles expriment des marqueurs d'activation CD23, CD30, CD39 et Ki24, des molécules d'adhérence leucocytaire non spécifiques CD11a/CD18 (LFA1), CD54 (ICAM1) et CD58 (LFA3), et les neuf protéines virales de latence. Ce phénotypc a été défini par A. Rickinson comme étant la latence de type III $[19,20]$. Dans ce type de latence, les ARN messagers des EBNA sont initiés à partir des promoteurs $C p$ et $W p$, et sont produits par épissage alternatif [21]. Les cellules des lignées de lymphome de Burkitt infectées par l'EBV sc multiplient en gélose scmi-molle et induisent des tumeurs chez la souris nude. En culture, elles ont un aspect monomorphe. Leur phénotype correspond à celui des lymphomes de Burkitt, exprimant CD10 et CD77, sans marqueur d'activation. Les molécules d'adhérence CD11a/CD18 et CD54 sont très faiblement exprimées et CD58 n'est pas détecté [22]. Seule la protéine de latence viralc EBNA1 est exprimée, et ce phénotype correspond à la latence de type I d'après la caractérisation de A. Rickinson [20]. L'ARN messager d'EBNA1 est trans- 


\section{RÉFÉRENCES}

17. Katz DA, Baumann RP, Sun R, Kolman JL, Taylor N, Miller G. Viral protein associated with the Epstein-Barr virus transactivator Zcbra. Proc Natl Acad Sci USA 1992 ; 89 : 378-82

18. Hsu DH, De Wall Malefyt R, Fiorentino DF, et al. Expression of interleukin-10 activity by Epstcin-Barr virus protcin BCRF1. Science $1990 ; 250$ : 830-2.

19. Kicff E, Licbowitz D. Epstein-Barr virus and its replication. In : Fields $\mathrm{BN}$, Knipc DM, et al. cds. Virology, 2nd ed. New York : Raven Press, 1990: 1889-920.

20. Rowe M, Lear AL, Croom-Carter D, Davics $\mathrm{AH}$, Rickinson AB. 'Threc pathways of Epstcin-Barr virus genc activation from EBNA1 positive latency in B lymphocytes. J Virol $1992 ; 66$ : 122-31.

21. Woisctschlager M, Strominger JI, Speck SH. Mutually exclusive use of viral promoters in Epstein-Barr virus latently infected lymphocytes. Proc Natl Acad Sci USA 1989 ; 86 : 6498-502.

22. Billaud M, Calender A, Scigneurin JM, Lenoir GM. LFA1, LFA3, and ICAM 1 expression in Burkitt's lymphoma. Lancet 1987 ; ii : 1327-8.

23. Sample J, Brooks L, Sample C, et al. Restricted Epstcin-Barr virus protein expression in Burkitt's lymphoma is duc to a different Epstcin-Barr nuclear antigen 1 transcriptional initiation sitc. Proc Natl Acad Sci USA 1991 ; 88 : 6343-7.

24. Gregory CD, Murray RJ, Edwards CF, Rickinson AB. Down regulation of ccll adhesion molecules LFA3 and ICAM1 in Epstcin-Barr virus-positive Burkitt's lymphoma underlies tumor cell cscape from virus-spccific T-cell surveillance. J Exp Med 1988 ; 167 : 1811-24.

25. Ragot $T$, Fincrty S, Watkins PE, Pcrricaudet M, Morgan AJ. Replicationdefective recombinant adenovirus expressing the Epstcin-Barr virus envcloppc glycoprotcin gp340/220 induces immunity against EBV-induced lymphomas in the cottontop tamarin. J Gen Virol 1993 (sous presse).

26. Rowe M, Young LS, Crocker J, Stokes $\mathrm{H}$, Henderson S, Rickinson AB Epstcin-Barr virus associated lymphoproliferative discase in the SCID mouse model : implication for the pathogencsis of EBV positive lymphomas in man. I Exp Med $1991 ; 173: 147-58$

27. Kicf? E, Lcibowitz D. Epstein-Barr virus. Biology, pathogencsis and medical aspects. In : Ficlds BN, Knipc DM, et al., cds. Virology, 2nd cd. New York: Raven Press, 1990: 1921-58.

28. Moss DJ, Wallace LE, Rickinson AB Epstein MA. Cytotoxic T-cell recognition of Epstein-Barr virus-infected B-cclls. I. Spccificity and HLA restriction of effector cclls reactivated in vitro. Eur J Immunol 1981; 11 : 686-93.

29. Murray RJ, Kurilla MG, Griffin HM, et al. Human cytotoxic $T$-cell responses against Epstcin-Barr virus nuclcar antigens demonstrated by using recombinant vaccinia viruses. Proc Natl Acad Sci USA 1990 87: 2906-10. crit à partir du promoteur $F p$ [23]. Après plusieurs passages en culture, certaines lignées peuvent acquérir un phénotype identique à celui des lignées lymphoblastoïdes. Quatre groupes de lignées de lymphome de Burkitt ont été individualisés selon leur immunophénotype, allant du phénotype du lymphome de Burkitt $\left(\mathrm{CD} 10^{+}, \mathrm{CD}_{77^{+}}\right)$à celui des lignées lymphoblastoïdes (CD10-, CD77-, $\mathrm{CD}_{23}{ }^{+}, \mathrm{CD}_{30}{ }^{+}, \mathrm{CD} 39^{+}, \mathrm{Ki}_{24}{ }^{+}$, $\mathrm{CD} 11 \mathrm{a} / \mathrm{CD} 18^{+}, \mathrm{CD}_{4}{ }^{+}, \mathrm{CD}^{+} 8^{+}$ [24]. Récemment, trois voies d'activation du cycle lytique à partir des ccllules de Burkitt en latence de type I ont été décrites après traitement par le TPA (tétradécanoyl phorbol acétate): le cycle lytique peut ainsi être activé soit directement, soit après passage par la latence de type III ou par la latence de type II. Ce dernier type de latence est caractérisé par l'expression des protéines virales LMP ct EBNA1, sans expression des autres EBNA [20].

\section{Les modèles d'étude chez I'animal}

Le singe tamarin infecté par l'EBV développe, dans un tiers des cas, un syndrome lymphoprolifératif similaire aux syndromes lymphoprolifératifs rencontrés chez les immunodéprimés. La maladic du singe tamarin sert de modèle d'étude à l'élaboration de vaccins recombinants tels ceux développés dans des vecteurs adénovirus [25].

Les souris scid/scid CB-17 (severe combined immunodeficiency) constituent actuellement un excellent modèle pour l'étude du rôle de l'EBV dans lc développement des syndromes lymphoprolifératifs chez les immunodéprimés et pour l'élaboration de nouvelles stratégies thérapeutiques. Ces souris mutantes sont caractérisées par l'absence de lymphocytes $\mathrm{T}$ et B mûrs réalisant un déficit immunitaire sévère. Les greffes inter-espèces sont parfaitement tolérées et le déficit immunitaire peut être corrigé après injection intrapéritonéale de leucocytes humains (hu-PBL-SCID). Les souris $h u-P B L-S C I D$ reconstituées à partir de leucocytes de porteurs sains de l'EBV développent des proliférations lymphoïdes rapidement fatales. Celles-ci sont multifocales et histo- logiquement semblables aux lymphomes à grandes cellules observés chez les immunodéprimés après transplantation d'organe. L'immunophénotype et l'expression des protéines virales ressemblent à ceux des lignées lymphoblastoïdes. Toutefois, les antigènes de réplication ZEBRA et VCA peuvent être plus souvent détectés. Ces proliférations lymphoïdes sont polyclonales ou oligoclonales [26].

\section{Les défenses immunitaires anti-EBV}

Le système immunitaire joue un rôle fondamental dans le contrôle de l'infection et de la prolifération des lymphocytes B. La réponse humorale produit des anticorps dirigés contre les antigènes viraux VCA, EA et MA qui apparaissent rapidement après la primo-infection [27]. Les anticorps anti-VCA sont les premiers détectés et persistent pendant toute la vie. Les anticorps anti-EA sont produits de façon transitoire et inconstante. Les anticorps anti-EBNA apparaissent en 1 à 3 mois et peuvent disparaître totalement, en particulier chez l'immunodéprimé. Ils témoigneraient du développement d'une réaction immunitaire cellulaire anti-EBV. Les lymphocytes $\mathrm{T}$ cytotoxiques CD8 + spécifiques de l'EBV sont dirigés contre les antigènes de latence virale cxprimés par les cellules infectées [28]. La reconnaissance des déterminants antigéniques d'EBNA3 et, à un moindre degré, de LMP et d'EBNA2 est restreinte par les antigènes HLA de classe I [29]. La protéine EBNA1 n'est pas reconnue par le système immunitaire. Les réponses immunes anti-EBV réalisent un équilibre entre le virus et l'hôte. La rupture de cet équilibre dans certaines conditions pathologiques de déficit immunitaire ou d'activation cellulaire B polyclonale permettra la prolifération non contrôlée de lymphocytes infectés par l'EBV pouvant aboutir au développement d'une prolifération lymphomateuse.

\section{$L^{\prime} E B V$ et les proliférations lymphoïdes}

In vivo, l'infection par l'EBV est associée à des proliférations lymphoïdes bénignes comme la mononucléose 
infectieuse, ou à des proliférations malignes. Le lymphome de Burkitt africain et les lymphomes survenant au cours des déficits immunitaires sont les plus fréquemment observés. Récemment, cette association a été montrée dans les lymphomes $\mathrm{T}$ périphériques et dans certaines catégories de maladie de Hodgkin. En revanche, elle reste faible dans les lymphomes non hodgkiniens de la population générale [30].

\section{L'EBV et le lymphome de Burkitt}

C'est à partir d'un lymphome de Burkitt, cancer le plus fréquent de l'enfant dans les zones d'endémie palustre d'Afrique équatoriale, que l'EBV a été découvert [1]. La placc particulière de l'EBV dans le lymphome de Burkitt est liée à la fréquence de son association aux lymphomes de Burkitt africains, supérieure à $90 \%$, et à la démonstration de l'implication de ce virus dans la cancérogenèse [31]. Défini par des critères histopathologiques comme une prolifération lymphomateuse diffuse de cellules lymphoïdes de taille moyenne à noyau arrondi, à cytoplasme basophile contenant des vacuoles, associée à des histiocytes macrophages réalisant un aspect de " ciel étoilé ", le lymphome de Burkitt possède des marqueurs phénotypiques et moléculaires particuliers. Il s'agit d'une prolifération monoclonale de cellules lymphocytaires B caractérisées par une translocation impliquant le chromosome 8 (8q24) et le chromosome $14 \mathrm{t}(8 ; 14)$ (q24;q32), ou les chromosomes $22 \mathrm{t}(8 ; 22)$ (q24;q11) et 2 t $(2 ; 8)$ (q24;q11) pour les translocations variantes. Ces translocations impliquent l'oncogène $c$-myc sur lc chromosome 8 , et les gènes des chaînes lourdes et légères des immunoglobulines sur les chromosomes 14 , 22 et 2 [32]. L'EBV n'est pas directement impliqué dans ces translocations qui sont observées tant dans le lymphome de Burkitt africain que dans le lymphome de Burkitt sporadique, où la fréquence d'association à l'EBV est inférieure à $20 \%$. Le lymphome de Burkitt est un modèle de développement multifactoriel et en plusieurs étapes de la transformation maligne, pour lequel différents scénarios ont été proposés. Pour G. Klein $\mathrm{m} / \mathrm{s} n^{\circ} 6-7$ vol. 9, juin-juillet 93
[33], l'EBV serait le premier événement permettant une prolifération de cellules B infectées mal contrôlées par le système immunitaire $\mathrm{T}$ déficitaire lors de l'infection palustre. Cette prolifération de lymphocytes B serait suivie par l'apparition d'événements cytogénétiques. $G$. Lenoir et $G$. Bornkamm [34] proposent une séquence différente où la stimulation lymphocytaire B liée au paludisme serait le premier événement suivi par la survenue des anomalics chromosomiques. L'EBV serait alors un événement supplémentaire et aléatoire rendant les cellules autonomes. Trois éléments sont fondamentaux pour l'analyse physiopathologique du

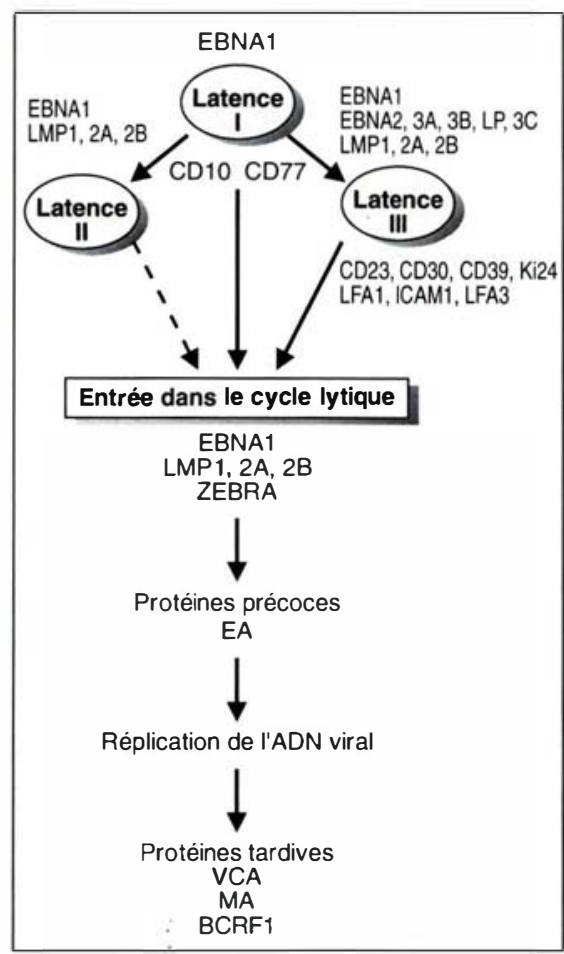

Figure 2. Les trois voies de l'activation du cycle lytique de I'EBV à partir de la forme de latence I dans les lymphocytes B. L'activation de la réplication de l'EBV, spontanée ou chimique, induit la transcription du gène codant pour la protéine transactivatrice ZEBRA. ZEBRA induit l'expression des gènes précoces de l'EBV, la réplication de I'ADN viral et l'expression des gènes tardifs. Des facteurs additifs de l'hôte et d'autres facteurs viraux sont nécessaires pour l'entrée de I'ADN viral en phase de synthèse, l'expression des gènes tardifs et la maturation du virus. (D'après G. Miller, 1992 et $M$. Rowe, 1992.)

lymphome de Burkitt : le stade de différenciation et l'état fonctionnel de la cellule, l'cxpression des gèncs de latence et de réplication de l'EBV, et les réponses immunes anti-EBV. La cellule du lymphome de Burkitt exprime le CD10, le CD77 et serait normalement localisée au sein de la zone sombre du centre germinatif des follicules lymphoïdes. Le rôle de l'EBV dans la transformation maligne de la ccllule du lymphome de Burkitt n'est pas complètement élucidé, mais celui d'EBNA1 et des EBER dans le maintien de la transformation maligne de ces cellules semble déterminant [23]. L'cxpression des protéines virales restreinte à EBNA1 et l'expression faible ou nulle des molécules d'adhérence permettraient aux cellules du lymphome de Burkitt d'échapper à l'immunosurveillance $\mathrm{T}$ spécifique du virus [22].

L'EBV, les lymphoproliférations et les lymphomes après déficits immunitaires congénitaux ou iatrogènes La fréquence de l'association à l'EBV est une des caractéristiques des lymphoproliférations et des lymphomes non hodgkiniens ( $\mathrm{LNH}$ ) survenant au cours des déficits immunitaires congénitaux du syndrome lymphoprolifératif lié au chromosome $X$ [35] et des transplantations d'organe [36]. En dehors de quelques cas de lymphomes $\mathrm{T}$, ces lymphoproliférations et lymphomes non hodgkiniens se développent dans plus dc $80 \%$ des cas aux dépens de cellules $B$ infectées par l'EBV non contrôlées par le système immunitaire. L'émergence d'un clone pourrait résulter soit d'un second événcment génique (mais un réarrangement de l'oncogène $c-m y c$ est rarement observé), soit d'un avantage prolifératif, comme cela a été montré chez la souris SCID [26]. Ces lymphoproliférations et $\mathrm{LNH}$ sont particuliers par la fréquence des localisations extra-ganglionnaires et par leur hétérogénéité morphologique et immunophénotypique avec des aspects polyclonaux, oligoclonaux ou monoclonaux. Un large spectre morphologique est décrit, allant de l'hypcrplasie polyclonale aux LNH à grandes cellules ou immunoblastiques avec différenciation plasmocytaire, monomorphes et monoclonaux. En raison 


\section{RÉFÉRENCES}

30. Hamilton-1)utoit S, Pallesen G. A survey of Epstein-Barr virus gene expression in sporadic non Hodgkin's lymphomas. Detec tion of Epstcin-Barr virus in a subset of peripheral T-cell lymphomas. Am J Pathol $1992 ; 140: 1315-25$

31. De Thé G. Epstein-Barr virus and Burkitt's lymphoma worldwide : the agent revi sited. In : I,cnoir GM, O'Connor G, Olweny CI, cds. Burkitt's Lymphoma : Human Model Cancer. Lyon : IARC scientific publications, $1985: 165-76$

32. Bernheim A, Berger $R$, Lenoir $G$ Cytogenetic studies on African Burkitt's lymphoma cell lines $\mathrm{t}(8 ; 14), \mathrm{t}(2 ; 8)$ and $\mathrm{t}(8 ; 22)$. Cancer Genet Cytogenet 1981; 3 $302-15$

33. Klein G. Defense of the " old "Burkit lymphoma scenario. In : Klein $G$, ed Advances in Viral Oncology. New York : Raven Press, 1987 : 207-11.

34. Lenoir G, Bornkamm GW. Burkitt's lymphoma, a human cancer model for the study of the multistep development of cancer : proposal for a new scenario. In Klein G, ed. Advances in Viral Oncology. New York: Raven Press, 1987: 173-206.

35. Gatti RA, Good RA. Occurrence o malignancy in immunodeficiency discase Cancer 1971; 28 : 89-98.

36. Penı I. Cancer complicating organ transplantation. N Engl J Med $1990 ; 323$ 1767-9

37. I ocker J, Nalesnik M. Molecular genetic analysis of lymphoid tumors arising after organ transplantation. Am I Pathol 1989 135: 977-87

38. Thomas JA, Hotchin NA, Allday MJ et al. Immunohistology of Epstein-Barr virus associated antigens in B-cell disorders from immunocompromised individuals. Transplant $1990 ; 49: 944-53$

39. Katz BZ, Raab-Traub N, Miller G Latent and replicating forms of Epstein-Barr virus DNA in lymphoma and lymphoproliferative discases. J Infect Dis $1989 ; 160$ 589-98.

40. Swinnen IJ, Costanzo-Nordin MR, Fisher SG, et al. Increased incidence of lymphoproliferative disorders after immunosuppression with the monoclonal antibody OKT3 in cardiac transplant recipients. $N$ Engl I Med 1990 ; 323 : 1723-8.

41. Fischer A, Blanche S, I,ebidois J, et al. Ireatment of severe B-lymphocyte proliferative syndrome af ter bone marrow trans plantation with anti-B-cell monoclonal antibodies. N Engl J Med 1991 ; 334 : 1451-6. 42. Hamilton-Dutoit SJ, Raphacl M, Audouin J, et al. In situ demonstration of Epstcin-Barr virus small RNAs (EBER1) in AIDS related lymphomas : correlation with tumor morphology and primary site. Blood 1993 (sous presse).

43. Pallesen G, Hamilton-Dutoit SJ, Rowe M, et al. Expression of Epstein-Barr virus replicative proteins in AIDS-related non Hodgkin's lymphoma cells. I Pathol 1991 ; 165 : 289-99.

44. Su I, Hsich HC, Lin KH, et al. Aggressive peripheral 'l'-cell lymphomas containing Epstein-Barr viral DNA : a clinicopathological and molecular analysis. Blood 1991 dc cette hétérogénéité, l'analyse de ccs tumeurs doit comporter une étude morphologique et immunophénotypique, et l'analyse dc la clonalité déterminée par celle des gènes des immunoglobulines et du génome de l'EBV [37]. Leur immunophénotype est souvent similaire à celui des lignées lymphoblastoïdcs, avec une augmentation de l'expression des marqueurs d'activation, des moléculcs d'adhérence et des gènes de latence de l'EBV, EBNA et LMP [38]. L'EBV épisomique, caractéristique de la forme latente du virus, est observé dans tous les cas. Toutefois, des fragments linéaircs et l'expression de la protéine ZEBRA, caractéristiques de l'cntréc en phase lytique, peuvent parfois être détectés [39]. Après transplantation d'organe, la fréquence d'apparition d'une lymphoprolifération varie selon le type de greffc et le traitement immunosuppresseur. Elle va de $0,6 \%$ après greffc de moellc à $4,6 \%$ aprc̀s transplantation cardio-pulmonaire, et peut dépasser $30 \%$ avec un délai moyen d'apparition de 4,4 mois après l'administration d'anticorps anti-CD3 associés aux corticoïdes, à la ciclosporine et à l'azathioprinc [40]. Les traitements conventionnels radiothérapiques et chimiothérapiques sont déccvants. L'utilisation d'anticorps monoclonaux dirigés contre des déterminants antigéniques de la lignée $\mathrm{B}$, CD21 et CD24, a permis l'obtention de régressions durables de ces lymphoproliférations [41].

\section{Les lymphomes malins non hodgki- niens associés au SIDA}

Ces LNH de haute malignité sont de trois types histopathologiques: les lymphomes dc Burkitt, les LNH à grandes cellules ct les LNH immunoblastiques dont les lymphomes cérébraux. Le risque de survenue d'un LNH au cours de l'infection par le VIH est en moyenne 60 fois plus élcvé que dans la population générale, et, pour des localisations particulièrcs commc le système nerveux central ou pour certains aspects histologiques comme le lymphome de Burkitt, ce risque est multiplié par 1000 . La fréquence de l'association avec l'EBV varic selon la localisation et le type histologique du lymphome [42]. Détecté dans tous les cas de lymphome cérébral primitif, l'EBV cst présent dans $50 \%$ des cas de LNH à grandes cellules et dans $40 \%$ des cas de lymphomes de Burkitt. Les lymphomes de Burkitt ont un phénotype similaire à cclui des lymphomes de Burkitt associés à l'EBV de la population générale. Seul EBNA1 est exprimé, correspondant à la latence de type I, avec une diminution de l'expression des molécules d'adhérence, sans cxpression des moléculcs d'activation. Les LNH à grandes cellules et immunoblastiques expriment les trois formes de latence - I, II et III - ainsi que les moléculcs d'adhérencc ct d'activation (figure 3). Ce dernier phénotype est proche de celui des lignées lymphoblastoïdes. Dans certains cas, l'cxpression du gène BZLF1, mise en évidencc par la révélation de la protéine ZEBRA, est en faveur de l'cntrée dans lc cycle lytiquc d'une catégorie de cellules infectécs par l'EBV [43]

\section{L'EBV et les lymphomes $T$ péri- phériques}

Paradoxalcment, les LNH T périphériques obscrvés au sein de la population générale sont plus fréquemment associés à l'EBV que lcs lymphomes B [30]. La préscnce de l'EBV au scin des cellules $\mathrm{T}$ a été initialcment obscrvéc dans $20 \%$ des cas de LNH T de la population de Taiwan [44]. Unc étude curopécnne réccnte a montré la préscncc do l'EBV dans les cellules tumorales de $10 \%$ des LNH T. Ces cas de lymphomes $\mathrm{T}$ portent le phénotype CD8 ${ }^{+}$[45]. Dans les granulomes malins centrofaciaux constitués de lymphocytes de phénotype CD8+, la fréquence de cette association est supérieure à $90 \%$ et les protéines EBNA2 et LMP pcuvent être cxprimécs, rendant compte du rôle de l'EBV dans ces LNH [46].

\section{L'EBV et les lymphomes anaplasi- ques à grandes cellules}

Ces LNH exprimant la molécule d'activation CD30, dont l'augmentation de l'expression peut être liéc à l'infection par l'EBV, sont fréquemment associés à ce virus, quel que soit leur phénotype, $\mathrm{T}$ ou B [47]. 
L'EBV et la maladie de Hodgkin

Les données épidémiologiques et sérologiques ont fait suggérer un lien entre la maladie de Hodgkin et l'EBV, puis l'utilisation des techniques d'hybridation in situ a montré la présence du génome de l'EBV au sein des cellules de Sternberg [48]. Les produits des gènes de latence virale sont fortement exprimés dans $50 \%$ des cas et dans les types histologiques avec cellularité mixte et avec sclérose nodulaire. Les cellules de Sternberg possèdent un grand nombre d'ARN EBER et une intense expression de LMP1 sans expression d'EBNA2 correspondant à la latence de type II, également observée dans les cancers indifférenciés du nasopharynx et dans des lymphomes associés au SIDA [49]. Quelques cellules de Sternberg expriment la protéine ZEBRA, indiquant l'entrée du virus dans le cycle lytique, mais aboutissant rarement à la production de virions [50]. La maladie de Hodgkin associée au SIDA représente une situation particulière où l'EBV a été détecté dans tous les cas analysés [51]. Chez les sujets immunocompétents, il n'a pas été observé de différence significative de l'évolution clinique en fonction de la présence de l'EBV [52].

\section{Conclusion}

De très nombreuses associations entre l'EBV et les proliférations lymphoïdes ont été récemment rapportées, avec la mise en évidence du génome viral au sein de la population tumorale. Les cellules infectées sont de nature, de stade de différenciation et d'états fonctionnels différents. L'EBV peut ainsi infecter les cellules B avant le stade de réarrangement des gènes des immunoglobulines [53], perturbant leur maturation et les rendant incapables d'exprimer les chaînes lourdes des immunoglobulines [54]. Des cellules immatures peuvent acquérir, après infection, un phénotype de cellules activées, l'EBV jouant vraisemblablement un rôle dans ces modifications pathologiques. De plus, dans certaines conditions, de nombreuses cellules inflammatoires identiques à celles de la maladie de Hodgkin peuvent être associées à la prolifération lymphomateuse. Ces
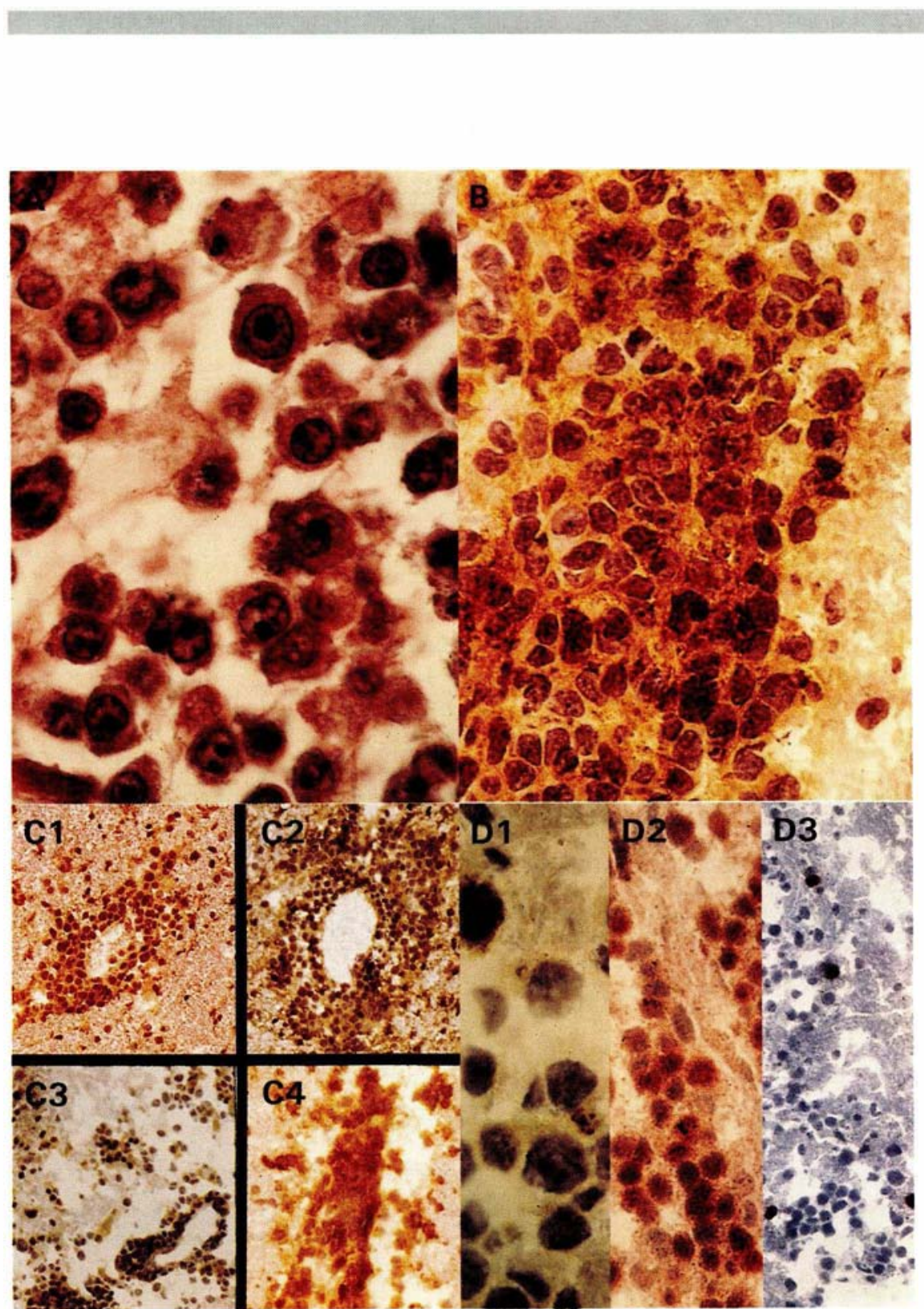

Figure 3. Lymphome cérébral primitif au cours du SIDA. Les cellules lymphomateuses immunoblastiques avec différenciation plasmocytaire (A) ont une topographie périvasculaire et sont de type B. Dans la majorité des cas, elles expriment les marqueurs d'activation cellulaire, ici CD23 (B), les molécules $d^{\prime}$ adhésion LFA1- $\alpha$ et $-\beta$, LFA3, ICAM (C1 à C4) et les protéines de I'EBV (D) : Les cellules qui expriment EBNA-2 (D2) sont plus nombreuses que celles qui expriment LMP-1 (D1). Dans certains cas, l'expression de la protéine ZEBRA (D3) indique l'entrée dans le cycle lytique d'un petit nombre de cellules infectées. 


\section{RÉFÉRENCES}

45. Richel DJ, Lepoutre JM, Kapsenberg JG, et al. Epstein-Barr virus in a CD8 positive T-cell lymphoma. Am J Pathol $1990 ; 136: 1093-9$.

46. Harabuchi Y, Yamanaka N, Akikastu $\mathrm{K}$, et al. Epstein-Barr virus in nasal Tcell lymphomas in patients with lethal midline granuloma. Lancet 1990 ; 335 : 128-30. 47. Herbst $H$, Dallenbach $F$, Hummel $M$, et al. Epstein-Barr virus DNA and latent gene products in Ki1 (CD30)-positive anaplastic large cell lymphoma. Blood 1991; $78: 2666-73$

48. Weiss LM, Movahed LA, Warnke RA, Purtilo DT, Sklar J. Epstein-Barr viral genomes in Reed Sternberg cells of Hodgkin's discase. N Engl J Med 1989; 32 : 502-6.

49. Pallesen G, Hamilton-Dutoit S, Rowe M, Young L. Expression of EpsteinBarr virus latent gene products in tumour cclls of Hodgkin's discasc. Lancet 1991 ; $337: 320-2$.

50. Pallesen G, Sandjev K, HamiltonDutoit SJ, Rowe M, Young LS. Activation of Epstein-Barr virus replicative genes in Hodgkin and Reed-Sternberg cells. Blood 1991; $78: 1162-5$.

51. Audouin J, Diebold J, Pallesen G. Frequent expression of Epstcin-Barr virus latent membranc protein-1 in tumour cells of Hodgkin's disease in HIV patients. J Pathol $1992 ; 167: 381-4$

52. Fellbaum E, Hansmann ML, Niedermeyer $\mathrm{H}$, et al. Influence of Epstein-Barr virus genome on patient in Hodgkin's disease. Am J Clin Pathol 1992 ; 98 : 319-23. 53. Katamine S, Otsu M, Tada K, et al. Epstein-Barr virus transforms precursor $\mathrm{B}$ cells even before immunoglobulin gene rearrangements. Nature 1984; 309 : 369-72. 54. Gregory C, Kirchgens C, Edwards C, et al. Epstein-Barr virus transformed human precursor B cell lines: altered growth phenotype of lines with germline or rearranged but non expressed heavy chain genes. Eur J Immunol 1987; 17 : 1199-207. phénomènes peuvent expliquer l'apparition de lymphome composite associant un LNH et une maladie de Hodgkin où l'EBV est impliqué. Ainsi, les aspects morphologiques, immunophénotypiques et anatomocliniques des proliférations lymphoïdes pourraient résulter non seulement de la nature de la cellule cible, mais aussi des interactions avec des facteurs viraux, comme l'EBV, et de l'état immunitaire de l'hôte

\section{Remerciements}

Nous tenons à remercier le professeur Jean-Claude Nicolas pour la lecture critique du manuscrit. L. M. a bénéficié de la médaille de l'internat des hôpitaux de Paris et remercie les professeurs Philippe Even, Jean-Jacques Hauw et Michel Poisson pour leurs encouragements.

\section{TIRÉS A PART}

L. Marelle.

\section{Summary}

Epstein-Barr virus and lymphoproliferations

The increased risk of Epstein-Barr virus (EBV)-associated lymphoproliferative disorders is due to the more frequent occurrence of immunodeficiency after immunosuppressive treatment or human immunodeficiency virus (HIV) infection. Furthermore highly sensitive EBV detection methods are applied, such as in situ hybridization and polymerase chain reaction. Besides African Burkitt's lymphoma and post transplant lymphoproliferative disorders associated with EBV in more than $90 \%$ of cases, acquired immunodeficiency syndrome (AIDS) related lymphomas represent a unique entity. Their association with EBV range from 10 to $100 \%$ of cases according to morphology and site. Recently, EBV has been detected in some T-cell lymphomas and in Hodgkin's disease in immunocompetent hosts. The analysis antiEBV immune responses, of latent and replicative viral gene expression, of EBV infected cell phenotype, and of genotypic changes will allow a better understanding of the role of EBV in lymphomagenesis.

\section{Le 40e Congrès de la Société Européenne de Culture de Tissus (ETCS) se tiendra du 4 au 8 juillet 1993 à RENNES, à la Chambre de Commerce et d'Industrie, sous le patronage, entre autres, de I'INSERM. \\ Le programme prévoit des conférences plénières, des tables rondes ainsi que des présentations affichées.}

\section{Les thèmes suivants seront abordés:}

- Cycle cellulaire: contrôle, transitions G1/S, G2/M ; cellules souches; facteurs de croissance, oncogènes.

- De la division à la différenciation cellulaire : gènes homéotiques; induction embryonnaire ; plasticité cellulaire ; division et différenciation des neurones, des hépatocytes et cellules glandulaires; interactions neurone/cellule musculaire, cellules endothéliales/tissus hôtes.

- Toxicité cellulaire : stress oxydatif; radicaux libres et peau; barrière épithéliale et pharmacotoxicologie; résistance aux drogues des cellules tumorales (MDR).

- Immortalisation/vieillissement : aspects moléculaires de la sénescence et apoptose; matrice extracellulaire, communications jonctionnelles et cancer. Les modèles de cultures cellulaires d'invertébrés et de poissons feront l'objet de tables rondes.

\section{Principaux conférenciers invités:}

T. Hunt (UK), V. Simanis (Suisse), L. Meijer (F), J. Pines (UK), H. Ponstingl (Allemagne), S. Thorgeirsson (USA), Y. Barrandon (F), J. Moscat (Espagnel, F. McKen zie (F), G. Evan (UK), J.M. Blanchard (F), G. Pinaev (Russie), J.F. Samain (F), J.P. Thiery (F), C. Niehrs (USA), C. Lampron (Canada), A. Snape (U.K.), A. TixierVidal (F), C. Wigley (UK), C. Barlovatz-Meimon (F), G. Darlington (USA), A. Guillouzo (F), B. Jégou (F), M. Meda (Suissel, M.R. Tyrrell (Suisse), L. Packer (USA), A. Haugen (Norvègel, C. Gespach (F), D. Thilo-Körner (Allemagne), P. Galla (Allemagne), F. Zucco (ltalie), M. Adolphe (F), J. Karisson (Suède), G. Zupi IItalie), M. Clynes (Irlandel, P. Morlière (F), J.L. Fryer (USA), M. Loir (F), A. Kahn (F), J. Campisi (USA), R. Schulte-Hermann (Autrichel, M. Bissell (USA), H. Yamasaki (F). Pour tout renseignement et inscription lavant le 15 mars 1993l s'adresser à: Bedin-Centonze Associées, 12, rue Berteaux Dumas, 92200 Neuilly. Tél.: (1) 46.97.19.71. - Fax. : (11) 47.72.28.52. 